\title{
Noninvasive mechanical ventilation improves the immediate and long-term outcome of COPD patients with acute respiratory failure
}

\author{
M. Confalonieri*, P. Parigi*, A. Scartabellati*, S. Aiolfi*, \\ S. Scorsetti*, S Nava**, L. Gandola*
}

Noninvasive mechanical ventilation improves the immediate and long-term outcome of COPD patients with acute respiratory failure. M. Confalonieri, P. Parigi, A. Scartabellati, S. Aiolfi, S. Scorsetti, S. Nava, L. Gandola. (CERS Journals Ltd 1996.

ABSTRACT: Noninvasive positive pressure ventilation (NPPV) has been proposed in COPD patients with acute on chronic respiratory failure (ACRF) in order to avoid endotracheal intubation and to improve immediate outcome, but long-term outcome of this therapeutic approach is still undefined.

We evaluated short- and long-term ( 1 year) outcome of early administration of NPPV in 24 patients with ACRF due to exacerbated COPD (Group A) in comparison with 24 matched historical-control patients treated conventionally (Group B). Patients of Group A were initially treated with NPPV via nasal mask in the presence of $\mathrm{pH} \leq 7.32$, and/or $\mathrm{Pa}, \mathrm{O}_{2}<7.98 \mathrm{kPa}$, and/or $\mathrm{Pa}_{\mathrm{a}}, \mathrm{CO}_{2}>7.18 \mathrm{kPa}$, plus signs of respiratory distress.

In-hospital survival rate was not significantly different in Group A vs Group B, but the patients treated with NPPV showed an earlier improvement in blood gases and a better $\mathrm{pH}$ and respiratory rate at discharge. Only 2 patients of Group A needed endotracheal intubation as compared with 9 of Group B. Hospital stay was significantly reduced in survivors of Group A vs Group B. Further severe relapses of ACRF in Group A were treated using NPPV. The number and length of further hospitalizations for pulmonary exacerbations were significantly higher in Group B compared with Group A. The survival rate at 12 months was significantly lower in Group B than in Group A $(50 \%$ vs $71 \%)$.

In conclusion, NPPV administration in patients with ACRF due to exacerbated COPD improves not only immediate but also long-term outcome.

Eur Respir J., 1996, 9, 422-430.

Patients with severe chronic obstructive pulmonary disease (COPD), especially those who have chronic respiratory failure, are vulnerable to a wide range of insults that lead to acute respiratory distress (acute on chronic respiratory failure - ACRF) that requires hospital admission and often mechanical ventilation [1]. Conventional treatment of this common condition includes oxygen supplementation, drugs, removal of secretions and, when necessary, mechanical ventilation. Even if conventional treatment is rapidly undertaken, patients often require prolonged hospitalization with poor prognosis when mechanical ventilation is not provided $[2,3]$.

Noninvasive positive pressure ventilation (NPPV) has recently been tested in COPD patients in order to avoid endotracheal intubation, but it is still difficult to define its success in patients with acute respiratory failure [4, 5]. The majority of the studies dealing with NPPV in exacerbations of COPD were not controlled [5]; in fact, only three studies considered a control group. VITACCA et al. [6] compared 29 COPD patients treated with NPPV with 35 nonmatched COPD patients treated conventionally.
*Divisione di Pneumologia, Ospedale Maggiore di Crema, Crema, Italy. **Divisione di Pneumologia, Centro Medico di Montescano, Montescano, Italy.

Correspondence: M. Confalonieri

Dept of Pneumology

Ospedale Maggiore di Crema I-26013 Crema

Italy

Keywords: Acute respiratory failure bi-level positive airway pressure chronic obstructive pulmonary disease noninvasive ventilation short- and long-term outcome

Received: February 281995 Accepted after revision October 51995
BROCHARD et al. [7] studied two strictly matched patient groups. The only randomized controlled study was performed by BотT et al. [8], using a volume-cycled nasal intermittent positive pressure ventilation mode. All these studies focused on the immediate outcome. This was improved in NPPV-treated patients. To our knowledge, no study has evaluated the long-term outcome of COPD patients treated with NPPV versus conventional therapy.

We recently reported our initial and encouraging experience in 28 consecutive patients with severe exacerbation of COPD treated with nasal bi-level positive pressure ventilation (BiPAP®) without a control group [9]. The aim of the present study was to evaluate the clinical efficacy of the early administration of nasal BiPAP in COPD patients with acute on chronic respiratory failure (ACRF) compared with conventional therapy, with regard to immediate and long-term outcome ( 6 and 12 months). The study design and setting is a prospective case series with strictly historically matched controls followed in a noninvasive monitoring unit located in a Division of Respiratory Diseases. 


\section{Methods}

We compared the short-term (in hospital) and long-term (12 months) outcomes in 24 nonconsecutive patients suffering from acute decompensated COPD receiving early administration of nasal BiPAP (Group A), with the outcomes of 24 historically matched control patients (Group B) receiving conventional therapy [10]. Pharmacological therapy did not differ in the two study groups (steroids, $\beta_{2}$-agonists, ipratopium bromide, theophylline, antibiotics, diuretics and cardiovascular drugs, when needed). Doxapram and other respiratory stimulants were not used. Oxygen was supplied with caution (beginning with fractional inspiratory oxygen $\left(F \mathrm{I}_{2}\right) \quad 24-28 \%$ and monitoring blood gases), and airway clearing was provided, when needed. Blood gases were measured in all patients on admission on breathing room air and with oxygen supplementation, and also after approximately $1 \mathrm{~h}$, after 1 day of treatment, at discharge, and during follow-up 4-5 measurements $\cdot \mathrm{y}^{-1}$.

An endotracheal intubation was possible at any time, in case of worsening of the respiratory conditions. Criteria for endotracheal intubation were similar in the two groups. "Traditional criteria" used in the historically-matched control group were equally applied to the patients of the prospective study, namely: Glasgow Coma Score (GCS) $<9$; severe hypercapnia $(>9.3 \mathrm{kPa})$; acute decreasing $\mathrm{pH}$ $<7.30$; signs of severe respiratory distress.

The study was approved by the local Ethics Committee. Patients' informed consent to noninvasive ventilation was obtained.

\section{Patients}

Twenty four patients (15 males and 9 females) admitted in the period 1993-1994 because of exacerbation of COPD with ACRF were treated with early administration of noninvasive BiPAP ventilation plus medical therapy (Group A). These patients were treated with BiPAP in presence of: arterial oxygen tension $\left(\mathrm{Pa}, \mathrm{O}_{2}\right)<7.98 \mathrm{kPa}$ (breathing room air); and/or arterial carbon dioxide tension $\left(P \mathrm{a}, \mathrm{CO}_{2}\right)>7.18 \mathrm{kPa}$ and/or $\mathrm{pH}<7.33$; and/or GCS $<13$; and/or respiratory rate $>30$ breaths $\cdot \mathrm{min}^{-1}$ plus other signs of respiratory distress (abdominal paradoxical movements, Hoover's sign, alternating abdominal and rib cage breathing, hypertonic secondary respiratory muscles, tachypnoea/bradypnoea).

The control patients $(n=24 ; 16$ males and 8 females $)$ were selected from a group of 72 patients (Group B). They were admitted in the two preceding years for the same diagnosis and conventionally treated $\left(\mathrm{O}_{2}+\right.$ drugs + mechanical ventilation by endotracheal intubation, if needed).

\section{Criteria of matching}

For each patient treated with BiPAP, a matching control patient was selected according to the following criteria: admission $P \mathrm{a}, \mathrm{CO}_{2}$ within $0.665 \mathrm{kPa}$ of the value for the treated patient when that value was $<9.31 \mathrm{kPa}$, and within 1.33 when the value was $\geq 9.31 \mathrm{kPa}$; arterial $\mathrm{pH}$ on admission within 0.03 of the value for the treated patient; prognostic score on admission (Acute Physiology And Chronic Health Evaluation (APACHE) II score) within three points; and age within $10 \mathrm{yrs}$ of that of the treated patient.

\section{Noninvasive ventilatory support}

A compact bi-level positive airway pressure ventilator (BiPAP, Respironics Inc., Murraysville, PA, USA) was used to provide pressure support ventilation (PSV) and external positive end-expiratory pressure (PEEP) could be added [11]. The device has a very sensitive flow trigger and, unlike conventional ventilators, it tolerates leaks. Inspiratory positive airway pressure (IPAP) and expiratory positive airway pressure (EPAP) could be set independently. BiPAP was used in spontaneous/timed $(\mathrm{S} / \mathrm{T})$ mode, which means in spontaneous breathing (as a PSV) with the possibility of passing to timed mode (controlled timed ventilation without patient triggering) in case the respiratory rate decreased below a preset value [12]. We did not use the standard BiPAP exhalation device (Whisper-Swivel TM; Respironics Inc., Murraysville, PA, USA) that has been shown to cause $\mathrm{CO}_{2}$ rebreathing [13], but the single patient use circuit with a continuous flow exhalation port (Respironics). Ventilation was regularly delivered using a continuous positive airways pressure (CPAP) nasal mask (Contour; Respironics) for a minimum period of $22 \mathrm{~h}$ on the first day of treatment; thereafter, the time of noninvasive ventilation was gradually reduced down to about $10-12 \mathrm{~h} \cdot \mathrm{day}^{-1}$, until a stable and satisfactory blood gas equilibrium was achieved. Nocturnal NPPV was then employed for a few more days, according to the discontinuation criteria shown in figure 1.

\section{Nursing care and patient assistance}

All the patients were admitted into a noninvasive respiratory monitoring unit located in our Division of Respiratory Diseases. The nasal mask was applied by nurses after having chosen the patient's proper mask size. Patients were encouraged to keep their mouths closed and, if needed, strappings aimed at closing the mouth were tested. A constant patient-caregiver interaction was pursued during the first period of nasal ventilation. For at least 30 min a physician stayed beside the patient and, during the following $3-4 \mathrm{~h}$, the patient was watched every 5-10 min (if the mask ventilation was well-tolerated). Patients' assistance and observation during ventilation was performed by nurses with the supervision of pneumonologists. A physician was responsible for the initial setting of pressures delivered by the ventilator. To facilitate acceptance by the patient of the ventilatory support via mask, a relative was allowed to stay near the patient to assist and to provide psychological support in the first hours/days. In fact, in the first hours after admission, hypercapnic patients experience most difficulty in tolerating ventilation masks. 


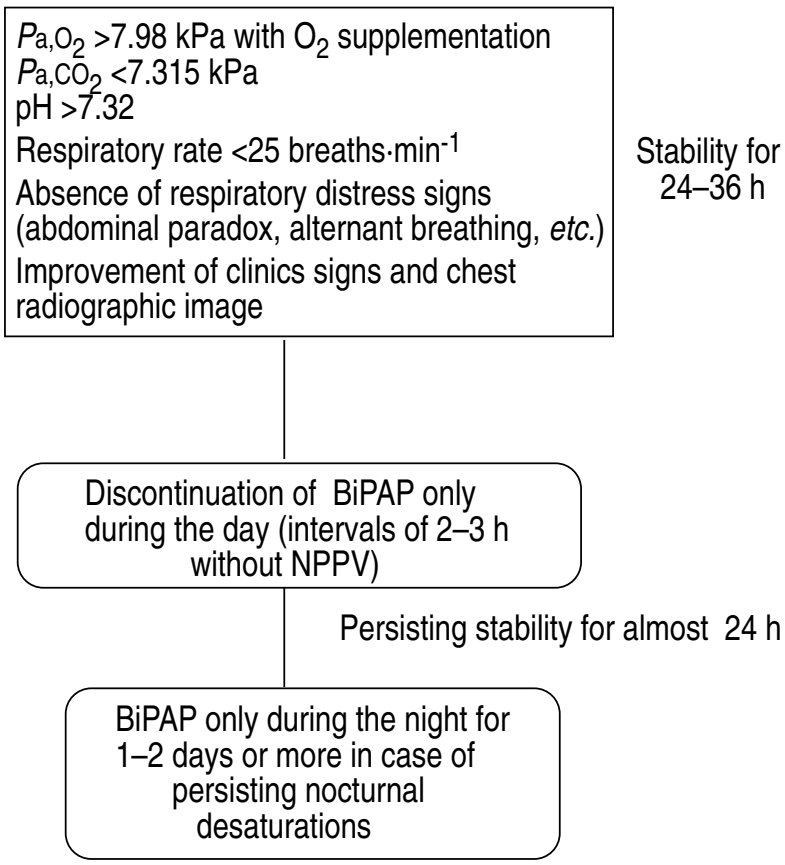

Fig. 1. - Criteria for discontinuation of noninvasive ventilation. $P \mathrm{a}, \mathrm{O}_{2}$ : arterial oxygen tension; $\mathrm{Pa}_{\mathrm{a}} \mathrm{CO}_{2}$ : arterial carbon dioxide tension; BiPAP: bi-level positive airway pressure; NPPV: noninvasive positive pressure ventilation.

\section{Data recording}

Immediate outcome. Evaluation of in-hospital mortality, occurrence of conventional mechanical ventilation by endotracheal intubation, need for tracheostomy, blood gas values and respiratory rate at discharge from hospital were recorded.

Duration of hospitalization (both in Intensive Care Unit (ICU) and pneumological ward). The discharge from the ICU in both groups of patients was decided by intensivists on the basis of respiratory autonomy from mechanical ventilation. Decision on the discharge from hospital was taken by pneumologists on the basis of achieving satisfactory clinical and blood gas stability. Clinical stability was defined as: 1) patient conscious and co-operative; 2) absence of hyperthermia; 3) stable haemodynamics (mean arterial blood pressure not varying by more than $10 \mathrm{mmHg}$ in the preceding 3 days); 4) stable arterial blood gases when breathing room air and/or oxygen supplementation (not varying by more than $5 \%$ in the preceding 3 days).

Number and duration of further hospitalizations following 1 yr from baseline admission. Only admissions for respiratory exacerbations or directly related to the baseline admission were considered.

Out-patient follow-up. After hospital discharge, the study and control patients were routinely followed as outpatients by the same physicians working in the pneumological ward and, thus, medical management was not different in Group A and Group B.

Out-patient pneumological visit plus arterial blood gas analysis occurred during the first 20-30 days after hospitalization and was repeated 3-4 times $\cdot \mathrm{y}^{-1}$. Simple exacerbations without complications or ACRF were treated with antibiotics and/or oral steroids. This has been the standardized follow-up procedure in our department since 1988. During further hospitalizations, the therapy regimen did not change for the two groups of patients with the exception of the use of NPPV during some severe exacerbation episodes with ACRF affecting Group A patients (6 out of 14 episodes=43\%).

\section{Statistics}

Baseline and follow-up data of noninvasively-ventilated patients and of controls were compared by analysis of variance (ANOVA) or Student's t-test and MannWhitney's nonparametric test. A comparison of in-hospital and long-term outcomes between the two groups of patients was made by a Chi-squared test with Yates' correction. The unpaired Student's t-test was carried out to evaluate group for group possible differences in hospitalization time in survivors. Comparisons between blood gas values on admission and at discharge in survivors were made by Student's paired t-test. Probability values less than 0.05 were considered significant. The Kaplan-Meier method was used to describe survival [14]. Differences in survival between groups were assessed using the log-rank test [15].

\section{Results}

\section{Patients}

Demographic and clinical characteristics of all the patients on admission are shown in tables 1 and 2 . Patients treated with BiPAP and those treated conventionally matched perfectly, as shown in table 1 .

The number of days during which BiPAP treatment was administered ranged 2-19, with a mean of $9.8 \pm 4$ days. Mean IPAP was $15 \pm 2 \mathrm{cmH}_{2} \mathrm{O}$ (range 10-20) and mean EPAP was $4 \pm 0.8 \mathrm{cmH}_{2} \mathrm{O}$ (range 3-6).

Side-effects observed in patients treated with noninvasive ventilation are shown in table 3 .

\section{Immediate outcome}

In-hospital survival rate was not significantly different in the treated versus the control group ( $88 \%$ vs $75 \%$, $\mathrm{p}=0.477$ ). Considering the avoidance of either death and endotracheal intubation as the most important treatment goal, the BiPAP treatment was successful in 20 patients $(83 \%)$ compared with 13 patients $(46 \%)$ of the conventionally treated group $(p=0.035)$. Two of the conventionally treated patients were discharged with a tracheostomy. 
Table 1. - Patients' data on admission (breathing room air) and short-term outcome (in hospital)

\begin{tabular}{|c|c|c|c|c|c|c|c|c|c|c|}
\hline $\begin{array}{l}\mathrm{Pt} \\
\text { No. }\end{array}$ & $\begin{array}{l}\text { Age } \\
\text { yrs }\end{array}$ & $\begin{array}{c}P \mathrm{a}, \mathrm{O}_{2} \\
\mathrm{kPa}\end{array}$ & $\begin{array}{c}P \mathrm{a}_{1} \mathrm{CO}_{2} \\
\mathrm{kPa}\end{array}$ & $\mathrm{pH}$ & $\begin{array}{c}\mathrm{HCO}_{3}^{-} \\
\mathrm{mmol} \cdot \mathrm{L}^{-1}\end{array}$ & APACHE II & $\begin{array}{c}f \mathrm{R} \\
\mathrm{br} \cdot \mathrm{min}^{-1}\end{array}$ & CGS & $\begin{array}{c}\mathrm{HR} \\
\text { beats.min }\end{array}$ & $\begin{array}{l}\text { Hospital } \\
\text { outcome }\end{array}$ \\
\hline $1 \mathrm{~A}$ & 73 & 5.719 & 9.976 & 7.34 & 40 & 21 & 52 & 12 & 100 & Dead \\
\hline $1 \mathrm{~B}$ & 74 & 4.389 & 9.576 & 7.32 & 30 & 22 & - & 15 & 100 & Success \\
\hline $2 \mathrm{~A}$ & 79 & 4.788 & 7.182 & 7.34 & 30 & 14 & 30 & 15 & 96 & Success \\
\hline $2 \mathrm{~B}$ & 79 & 6.118 & 7.182 & 7.35 & 30 & 16 & 32 & 13 & 88 & Dead \\
\hline $3 \mathrm{~A}$ & 66 & 5.719 & 10.108 & 7.28 & 36 & 25 & 32 & 11 & 60 & Success \\
\hline $3 \mathrm{~B}$ & 58 & 6.517 & 9.044 & 7.28 & 32 & 25 & 48 & 10 & 110 & Success \\
\hline $4 \mathrm{~A}$ & 66 & 3.857 & 9.044 & 7.27 & 29 & 14 & 12 & 13 & 92 & Success \\
\hline $4 \mathrm{~B}$ & 73 & 4.389 & 9.044 & 7.27 & 32 & 17 & 40 & 12 & 100 & Success \\
\hline $5 \mathrm{~A}$ & 71 & 4.921 & 9.709 & 7.29 & 36 & 19 & 46 & 15 & 76 & Success \\
\hline $5 \mathrm{~B}$ & 73 & 4.522 & 9.443 & 7.31 & 34 & 20 & 40 & 13 & 96 & Success \\
\hline $6 \mathrm{~A}$ & 67 & 4.788 & 8.645 & 7.30 & 34 & 21 & 38 & 12 & 95 & Success \\
\hline $6 \mathrm{~B}$ & 67 & 5.320 & 7.980 & 7.30 & 29 & 21 & - & 13 & 88 & Success \\
\hline $7 \mathrm{~A}$ & 66 & 5.852 & 7.448 & 7.35 & 24 & 20 & 34 & 15 & 95 & Success \\
\hline $7 \mathrm{~B}$ & 66 & 4.788 & 7.980 & 7.33 & 32 & 21 & - & 15 & 100 & Success \\
\hline $8 \mathrm{~A}$ & 75 & 5.054 & 9.709 & 7.29 & 36 & 20 & 40 & 13 & 100 & Success \\
\hline $8 \mathrm{~B}$ & 75 & 5.985 & 10.64 & 7.26 & 38 & 19 & 20 & 15 & 120 & Dead \\
\hline $9 \mathrm{~A}$ & 60 & 5.187 & 10.108 & 7.34 & 43 & 22 & 40 & 12 & 112 & Success \\
\hline $9 \mathrm{~B}$ & 60 & 4.256 & 9.443 & 7.31 & 34 & 22 & 32 & 13 & 120 & Success \\
\hline $10 \mathrm{~A}$ & 68 & 5.719 & 7.581 & 7.38 & 31 & 15 & 45 & 15 & 90 & Success \\
\hline 10B & 68 & 5.852 & 7.581 & 7.39 & 30 & 17 & - & 15 & 130 & Success \\
\hline $11 \mathrm{~A}$ & 67 & 5.719 & 12.502 & 7.18 & 36 & 21 & 28 & 12 & 100 & Success \\
\hline 11B & 59 & 5.187 & 13.965 & 7.15 & 34 & 24 & 48 & 12 & 100 & Success \\
\hline $12 \mathrm{~A}$ & 82 & 5.054 & 9.044 & 7.26 & 31 & 28 & 38 & 15 & 80 & Success \\
\hline 12B & 77 & 5.985 & 9.576 & 7.27 & 33 & 26 & - & 13 & 87 & Success \\
\hline $13 \mathrm{~A}$ & 63 & 6.118 & 7.581 & 7.34 & 46 & 16 & 32 & 15 & 88 & Success \\
\hline 13B & 63 & 6.517 & 6.916 & 7.36 & 30 & 14 & 34 & 15 & 68 & Success \\
\hline $14 \mathrm{~A}$ & 67 & 5.187 & 6.113 & 7.41 & 38 & 19 & 40 & 15 & 100 & Success \\
\hline 14B & 74 & 7.049 & 7.315 & 7.38 & 32 & 16 & 28 & 15 & 64 & Success \\
\hline $15 \mathrm{~A}$ & 66 & 5.985 & 8.645 & 7.32 & 33 & 18 & - & 14 & 92 & Success \\
\hline 15B & 76 & 7.049 & 7.980 & 7.32 & 30 & 19 & - & 12 & 100 & Success \\
\hline $16 \mathrm{~A}$ & 70 & 6.517 & 7.714 & 7.38 & 31 & 23 & 38 & 15 & 100 & Success \\
\hline 16B & 76 & 6.118 & 7.714 & 7.38 & 35 & 21 & 36 & 15 & 120 & Dead \\
\hline $17 \mathrm{~A}$ & 60 & 6.251 & 7.581 & 7.41 & 36 & 15 & 28 & 15 & 100 & Success \\
\hline 17B & 64 & 5.586 & 7.980 & 7.43 & 39 & 15 & 32 & 15 & 80 & Dead \\
\hline $18 \mathrm{~A}$ & 58 & 4.921 & 8.113 & 7.22 & 26 & 16 & 46 & 11 & 96 & Success \\
\hline 18B & 53 & 3.458 & 9.709 & 7.23 & 32 & 16 & 15 & 15 & 100 & Success \\
\hline $19 \mathrm{~A}$ & 56 & 3.591 & 11.970 & 7.21 & 30 & 21 & 28 & 15 & 104 & Dead \\
\hline 19B & 67 & 5.719 & 10.640 & 7.19 & 30 & 22 & 28 & 12 & 84 & Success \\
\hline $20 \mathrm{~A}$ & 72 & 5.985 & 7.714 & 7.22 & 22 & 17 & 46 & 15 & 98 & Success \\
\hline 20B & 73 & 6.650 & 8.379 & 7.22 & 26 & 14 & 32 & 14 & 100 & Success \\
\hline $21 \mathrm{~A}$ & 74 & 7.448 & 9.576 & 7.14 & 24 & 26 & 48 & 15 & 120 & Dead \\
\hline 21B & 65 & 6.650 & 10.640 & 7.13 & 28 & 24 & 22 & 13 & 110 & Dead \\
\hline $22 \mathrm{~A}$ & 65 & 7.182 & 10.640 & 7.23 & 37 & 23 & 44 & 13 & 100 & Success \\
\hline 22B & 66 & 6.118 & 10.374 & 7.24 & 37 & 22 & 24 & 13 & 115 & Dead \\
\hline $23 \mathrm{~A}$ & 56 & 4.522 & 10.640 & 7.26 & 34 & 15 & 32 & 12 & 96 & Success \\
\hline 23B & 60 & 3.990 & 10.507 & 7.36 & 45 & 15 & 40 & 12 & 112 & Success \\
\hline $24 \mathrm{~A}$ & 65 & 5.054 & 11.039 & 7.37 & 40 & 23 & 30 & 15 & 100 & Success \\
\hline 24B & 52 & 4.256 & 9.709 & 7.34 & 36 & 26 & 30 & 14 & 98 & Success \\
\hline
\end{tabular}

The patients are numbered according to their historically-matched pairs; the letters A and B indicate their group. GCS: Glasgow Coma Score. br: breaths. $\mathrm{Pa}, \mathrm{O}_{2}$ : arterial oxygen tension; $\mathrm{Pa}_{\mathrm{a}, \mathrm{CO}_{2}}$ : arterial carbon dioxide tension; APACHE: Acute Physiology And Chronic Health Evaluation; $f \mathrm{R}$ : respiratory rate; HR: heart rate; 
Table 2. - Baseline patient values on admission

\begin{tabular}{|c|c|c|c|}
\hline & $\begin{array}{c}\text { Group A } \\
\text { Added BiPAP }\end{array}$ & $\begin{array}{l}\text { Group B } \\
\text { Control }\end{array}$ & p-value \\
\hline Age yrs & $67 \pm 6$ & $68 \pm 7$ & 0.635 \\
\hline$P_{\mathrm{a}, \mathrm{O}_{2}} \quad \mathrm{kPa}^{*}$ & $5.46 \pm 0.91$ & $5.52 \pm 1.04$ & 0.844 \\
\hline$P \mathrm{a}, \mathrm{CO}_{2} \quad \mathrm{kPa}^{*}$ & $9.18 \pm 1.49$ & $9.11 \pm 1.58$ & 0.884 \\
\hline $\mathrm{pH}^{*}$ & $7.29 \pm 0.07$ & $7.29 \pm 0.07$ & 0.921 \\
\hline $\mathrm{HCO}_{3}^{-*}$ & $33.00 \pm 5.41$ & $32.44 \pm 4.64$ & 0.699 \\
\hline $\begin{array}{l}\text { APACHE II } \\
\text { score }\end{array}$ & $19.67 \pm 3.91$ & $19.17 \pm 3.99$ & 0.663 \\
\hline$f_{\mathrm{R}}$ breaths $\cdot \mathrm{min}^{-1}$ & $36 \pm 8$ & $31 \pm 7$ & 0.090 \\
\hline Mean $P_{\text {sys }} \mathrm{kPa}$ & $14.36 \pm 2.52$ & $13.70 \pm 1.8$ & 0.240 \\
\hline HR beats $\cdot \min ^{-1}$ & $96 \pm 12$ & $99 \pm 16$ & 0.260 \\
\hline Last FEV1 $\mathrm{L} \dagger$ & $1.03 \pm 0.49 \S$ & $1.08 \pm 0.51 \ddagger$ & 0.821 \\
\hline Last FVC L $†$ & $1.79 \pm 0.72 \S$ & $1.83 \pm 0.60 \ddagger$ & 0.915 \\
\hline Last $\mathrm{FEV} 1 / \mathrm{FVC} \dagger$ & $0.57 \pm 0.07 \S$ & $0.59 \pm 0.06 \ddagger$ & 0.259 \\
\hline
\end{tabular}

Values are presented as mean \pm SD. *: breathing room air; $\dagger$ : clinical stability; $\S$ : assessed in 20 out of 24 patients; $\$$ : assessed in 18 out of 24 patients. BiPAP: bi-level positive airway pressure. $P$ sys: systemic blood pressure; FEV1: forced expiratory volume in one second; FVC: forced vital capacity. For further abbreviations see legend to table 1 .

Only $2(8 \%)$ out of the patients treated with nasal BiPAP needed mechanical ventilation by endotracheal tube, whereas $9(38 \%)$ of the patients receiving conventional therapy underwent intubation and mechanical ventilation. Statistical analysis showed a significant difference $(p=0.046)$ in the occurrence of endotracheal intubation between the groups. Two Group A patients and three Group B patients died after having been evaluated by the intensive care physicians and found to be ineligible for conventional mechanical ventilation because of their age and/or poor prognosis.

In-hospital survivors with both modalities of treatment showed statistically significant changes $(\mathrm{p}<0.001)$ between baseline and withdrawal data of blood gases (breathing room air) and respiratory rate at rest (fig. 2). It is notable that $\mathrm{pH}, \mathrm{Pa}, \mathrm{O}_{2}$ and $\mathrm{Pa}, \mathrm{CO}_{2}$ improved earlier in BiPAP-treated patients than in controls $(\mathrm{pH}$ after $1 \mathrm{~h}$ $(\mathrm{p}<0.05)$ and after $24 \mathrm{~h}(\mathrm{p}<0.03) ; P_{\mathrm{a}}, \mathrm{CO}_{2}$ after 1 and 24 $\mathrm{h}(\mathrm{p}<0.001) ; \mathrm{Pa}_{\mathrm{a}} \mathrm{O}_{2}$ after $1 \mathrm{~h}(\mathrm{p}<0.01)$, respiratory rate $(f \mathrm{R})$ after 1 and $24 \mathrm{~h}(\mathrm{p}<0.001))$. At discharge, a significant difference was still observed in $\mathrm{pH}$ and $f \mathrm{R}(\mathrm{p}<0.01$ and $\mathrm{p}<0.001$, respectively).

\section{Duration of hospitalization}

The mean duration of hospital assistance was $16 \pm 4$ days (range 12-27 days) in the 21 Group A patients who had a favourable outcome, including one intubated patient, when compared with $31 \pm 16$ days (range 14-65 days) in the 18 Group B patients who had favourable outcomes $(p<0.001)$. The length of stay in the ICU was significantly shorter in the group of patients treated with BiPAP (1.2 \pm 4.3 vs 9.1 \pm 13.5 days; $\mathrm{p}=0.009)$.
Table 3. - Side-effects of mask ventilation, number of patients affected and mean duration of side-effects

\begin{tabular}{|c|c|c|c|}
\hline $\begin{array}{l}\text { Nasal mask } \\
\text { ventilation } \\
\text { side-effects }\end{array}$ & $\begin{array}{c}\text { Pts } \\
\text { affected } \\
\mathrm{n}\end{array}$ & $\begin{array}{c}\text { Duration } \\
\text { days }\end{array}$ & Notes \\
\hline Nose abrasion & 4 & 7 & \\
\hline Gastric distention & 1 & 1 & $\begin{array}{l}\text { Side-effect reversed } \\
\text { by use of nasogastric } \\
\text { tube }\end{array}$ \\
\hline Poor sleep & 3 & 4 & \\
\hline Eye irritation & 6 & 5 & $\begin{array}{l}\text { Decreased incidence } \\
\text { after use of } \\
\text { ComfortFlap® }\end{array}$ \\
\hline Rhinitis & 2 & 4 & \\
\hline
\end{tabular}

Number of further hospitalizations for pulmonary exacerbations

The Group A patients had a total of 14 hospitalizations in a year after the baseline admission (mean $0.6 \pm 0.8$ admissions patient $^{-1}$ ), whilst Group B patients had a total of 26 hospitalizations in the year (mean 1.4 $\pm 0.9 \cdot$ patient $^{-1}$ ). The difference between the groups was statistically significant $(\mathrm{p}=0.01)$.

Days spent in hospital per year were also significantly higher in Group B (450 days) than in Group A (153 days), with a mean of $25 \pm 22$ days $\cdot \mathrm{y}^{-1}$ per patient in Group $B$ versus $7 \pm 10$ days $\cdot$ year $^{-1}$ per patient in Group A ( $\mathrm{p}=$ 0.003).

\section{Blood gases during follow-up}

Data on blood gas values during follow-up were available 1 month after the first hospital discharge for all Group A patients (18 out of 18) and for 15 out of 17 Group B patients. Mean $\mathrm{pH}$ was 7.39 \pm 0.04 in Group A and 7.37 \pm 0.03 in Group B; mean $P \mathrm{a}_{1} \mathrm{CO}_{2} 4.83 \pm 1.2 \mathrm{kPa}$ and $5.98 \pm$ $0.83 \mathrm{kPa}$, and mean $\mathrm{Pa}, \mathrm{O}_{2} 7.72 \pm 0.76 \mathrm{kPa}$ and $7.64 \pm 0.93$ $\mathrm{kPa}$, respectively (no significant difference between the groups). Six months (range 4-8 months) after discharge these values were still not different. After $1 \mathrm{yr}$, blood gas values were available in 16 out of 17 Group A patients and in 9 out of 12 Group B patients, and again there were no significant differences between the groups.

\section{Six and 12 months survival}

Survival rate 6 months after admission was $71 \%$ in Group A and 54\% in Group B, and after 1 yr was $71 \%$ in Group A and 50\% in Group B. The differences between the groups were significant $(\mathrm{p}<0.05)$. The survival curves of the two groups are shown in figure 3 . The cause of death is reported in table 4. Most of the deaths occurred within the first 120 days after the former hospital admission. 

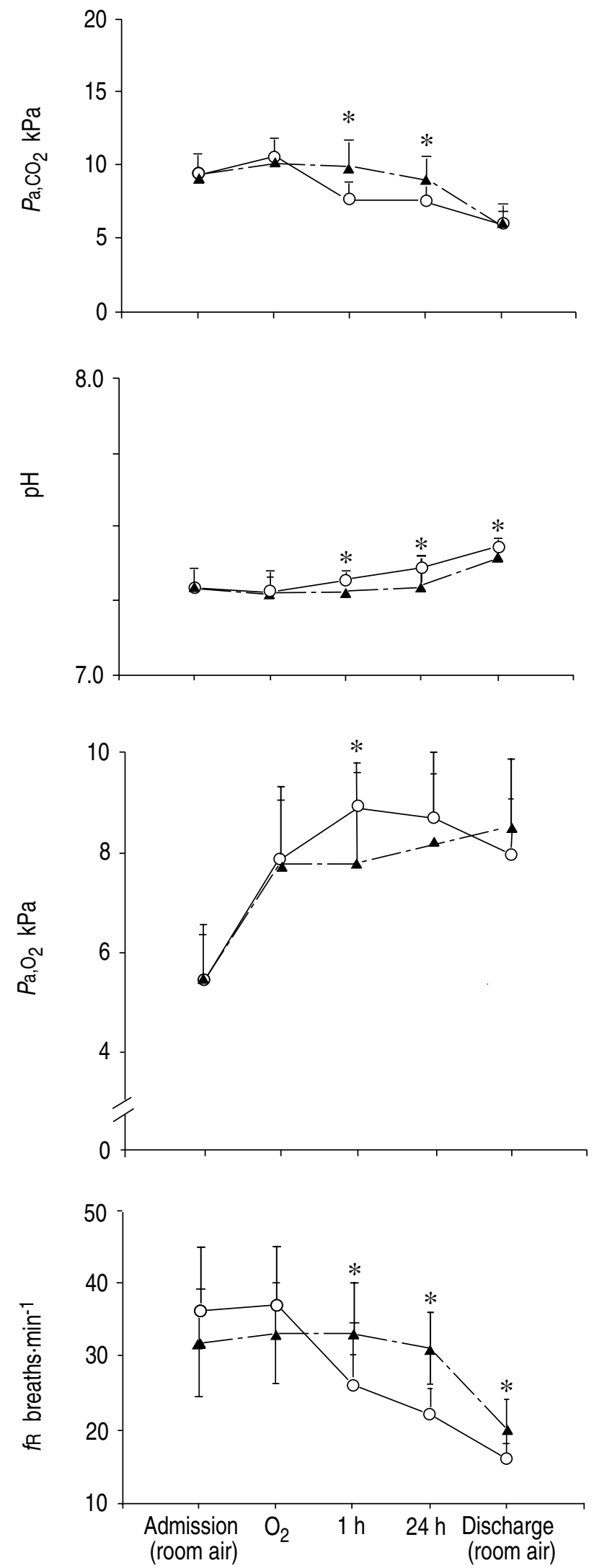

Fig. 2. - Blood gas data and respiratory rate $\left(f_{\mathrm{R}}\right)$ at different times in BiPAP treated patients (Group A) and in conventionally treated patients (Group B). O—O: Group A patients; $\mathbf{A}$ - Group B patients. For abbreviations see legend to figure 1.

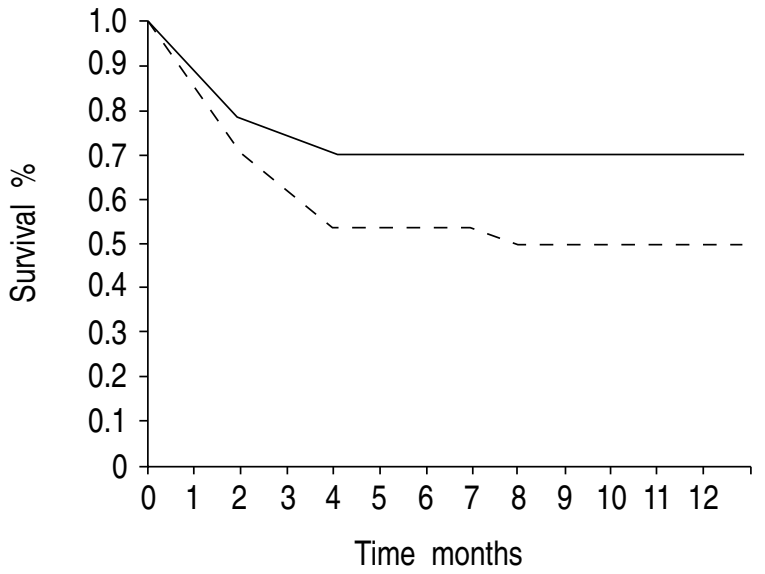

Fig. 3. - Survival of the two groups. ed patients); $-\quad$ : Group B (conventionally treated patients). BiPAP: bi-level positive airways pressure.

Table 4. - Cause of death and time of death after hospital admission in Group A and B patients (1 year observation period)

\begin{tabular}{cll}
\hline $\begin{array}{c}\text { Patient } \\
\text { No. }\end{array}$ & \multicolumn{1}{c}{ Cause of death } & $\begin{array}{c}\text { Time of death after } \\
\text { admission } \\
\text { months }\end{array}$ \\
\hline $\begin{array}{cl}\text { Group A } \\
\text { 1A }\end{array}$ & $\begin{array}{l}\text { Septic shock } \\
\text { pneumonia }\end{array}$ & 0.5 (in hospital) \\
6A & Exacerbation of COPD & 3 \\
9A & Exacerbation of COPD & 2 \\
12A & Pneumonia, cardiac & 1 \\
& failure & 1 \\
16A & Acute leukaemia & 0.8 (in-hospital) \\
19A & MOF & 0.2 (in-hospital) \\
21A & Stroke & \\
Group B & & 1.5 (in-hospital) \\
2B & Exacerbation of COPD & 1 \\
3B & Sudden death & 2 \\
7B & Pneumonia & 0.3 (in-hospital) \\
8B & MOF & 8 \\
14B & Exacerbations of COPD & 3 \\
15B & Pneumonia & \\
16B & Exacerbations of COPD & 0.3 (in-hospital) \\
17B & Cardiac failure & 0.3 (in-hospital) \\
20B & Pneumonia cardiac failure & 3 \\
21B & Exacerbation of COPD & 1.3 (in-hospital) \\
22B & Exacerbations of COPD & 3 \\
24B & Pneumonia, MOF & 0.2 (in-hospital) \\
\hline
\end{tabular}

COPD: chronic obstructive pulmonary disease; MOF: multiple organ failure.

\section{Discussion}

Our results confirm literature data concerning the efficacy of noninvasive positive pressure ventilation in avoiding endotracheal intubation and improving the immediate outcome of ACRF due to exacerbation of COPD in comparison with conventional treatment. The new data show that early administration of NPPV in severe relapses of ACRF may also improve the long-term outcome. This is 
the fourth controlled study on immediate outcome [6-8], but is the first, to our knowledge, on long-term outcome after an acute episode of respiratory failure in COPD patients.

Our study demonstrated that the early use of BiPAP improved survival (at 6 and 12 months after admission) and reduced the number of further hospital admissions for respiratory exacerbations and the time passed in hospital during the next year. The prognosis of advanced COPD treated with conventional medical therapy is rather poor $[2,16]$ and is even worse when mechanical ventilation becomes necessary [17]. In the literature, survival rates at one year of patients who underwent invasive mechanical ventilation ranged $34-49 \%$ in different studies, [18-20]. The only long-term study on noninvasively ventilated patients [21] showed a survival rate at $1 \mathrm{yr}$ very much higher than in other studies on patients treated conventionally either with medical therapy alone or by endotracheal mechanical ventilation. CORRADO and coworkers [22] used a negative pressure ventilation mode, the iron lung, to administer early treatment to COPD patients with acute respiratory failure (ARF) and at any relapse of ARF. Our results confirm the survival data of CORRADO and co-workers [22], although our patients treated with NPPV had a slightly lower survival rate at $1 \mathrm{yr}$. The difference may be explained by different ventilation modes, by difference in the size of the two study populations and by the fact that not all the relapses of ACRF in our study were treated with NPPV but only the severe ones. Obviously, it is not easy to explain the difference in survival rates on the basis of different treatment during one episode of ACRF. These differences may be due to the fact that the early use of NPPV shows an earlier improvement in blood gases.

Recently, MeECham Jones et al. [23] reported that nasal ventilation in acute exacerbations of COPD allows the safe use of supplemental oxygen with a well-controlled $P a, \mathrm{CO}_{2}$ in most patients, but in those with severe hypercapnia only relatively small falls or even increases in $P \mathrm{a}, \mathrm{CO}_{2}$ are obtained with the initiation of NPPV. These results are apparently in contrast with ours and those of other authors [7, 8, 24]; the explanation may be that patients with the highest $P \mathrm{a}, \mathrm{CO}_{2}$ levels are often more difficult to ventilate and to obtain adequate co-operation with NPPV, but also that the exhalation devices might be important [13]. However, it is interesting to point out that in our study, at hospital discharge, the noninvasively ventilated patients showed a $\mathrm{pH}$ higher and a respiratory rate lower than conventionally treated patients. Both phenomena may be based on previous unloading of the respiratory pump for several days with resulting recovery [25]. However, any speculation about respiratory muscle fatigue is somewhat hazardous since there is no clear evidence in the literature regarding COPD patients, at least concerning chronic respiratory muscle fatigue [26]. Another advantage of noninvasive ventilation in comparison to the presently available conservative therapies is the significantly reduced work of breathing for the COPD patient [27].

It must be stressed that a distinct advantage of NPPV is avoidance of intubation in most patients and shorten- ing of duration of hospitalization, thus reducing the possibility of several adverse effects associated with intubation and prolonged hospitalization. Invasive mechanical ventilation increases the risk of infectious complications, such as acute pulmonary exacerbations and pneumonia; in particular, it has been shown that the increased risk of developing pneumonia in patients receiving invasive ventilatory support is $1 \%$ per day of ventilation [28]. The presence of an endotracheal tube may, per se, bypass host defences, cause local trauma and inflammation and increase the risk of aspirating nosocomial pathogens from the upper airways [29]. A fundamental advantage of noninvasive ventilation may be the fact that it can preserve cough clearance, which is very important, especially for COPD patients with an exacerbated infection. In fact, insufficient cough clearance during invasive ventilation contributes greatly to the risk of infectious complications in COPD patients. No important and lasting side-effect was observed in the patients noninvasively ventilated.

Our study, given that it used historically-matched controls, presented well-known limits [30], even though it used strictly matching criteria. The principal problems related to the imperfect reproducibility of criteria for management and clinical decisions in historical groups. In our unit, except for the use of NPPV medical therapy strategies and follow-up procedures have not substantially changed over the last 4-5 yrs, being similar in Group A and Group B. It is also worth noting that: 1) the criteria for intubation in Group A were the same as those employed previously in Group B: and 2) the criteria for discharge from the ICU and from the pneumological ward have been quite homogenous in the course of the last few years. It should also be pointed out that even randomized controlled studies can present bias of distribution of the severity of the illness between the noninvasively ventilated patient group and the controls [31]. Furthermore, the lack of good matching can make a randomized trial less efficient than another trial not randomized but well-matched for several principal variables [32]. Our study population was, indeed, perfectly comparable for age, admission blood gases (breathing room air), severity score (APACHE II), and neurological status (GCS). It is notable that the matching criteria were similar to those employed by BROCHARD et al. [7], with the exception of APACHE II score [33] instead of the Simplified Acute Physiologic Score (SAPS). This kind of study may be useful as a "historical comparison" within the same Division of Respiratory Diseases, before and after the opening of an Intermediate Intensive Respiratory Care Unit.

Further, it is important to note that, besides the study of ViTACCA and co-workers [6], our study is the second controlled one on the administration of PSV with an added PEEP in acute COPD patients, but it is the first one using BiPAP®. The most quoted paper concerning BiPAP via mask in acute respiratory failure is that by PENNOCK et al. [34], who reported the results of a noncontrolled study showing the feasibility of this ventilatory technique in a medical ward, especially for postsurgical patients. The background of the use of noninvasive bi-level positive pressure ventilation (PSV + PEEP) in exacerba- 
tions of COPD with ACRF is based on physiological studies either on stable or acute patients. In patients with severe but stable COPD, it has been shown that BiPAP can improve respiratory pattern and blood gases, and unload ventilatory muscles during spontaneous breathing, reducing the effort of breathing and the oxygen cost [23]. NAVA et al. [35] demonstrated that nasal PSV improves diaphragmatic function in patients with severe stable COPD, and that this effect may be enhanced by the application of external PEEP. Recently, APPENDINI et al. [27] demonstrated that noninvasive ventilation delivered by CPAP added to PSV produces better results than CPAP or PSV alone with regard to the reduction of inspiratory effort, and as a consequence of working of breathing (WOB). Furthermore, the addition of a low external PEEP in severe COPD patients may counterbalance the positive pressure existing in the airways at the end of an expiration (autoPEEP), which is responsible for up to $70-80 \%$ of the total respiratory load $[36,37]$.

Our experience, and studies reported by PENNOCK and co-workers [38] and by Conway et al. [39], show the feasibility of nasal positive pressure ventilation in acutely decompensated COPD patients in a pneumological ward. It should be noted, that it is essential that conventional mechanical ventilation by endotracheal intubation would be available promptly. Chevrolet et al. [40] described noninvasive ventilation in acute patients as a time-consuming and difficult procedure for the personnel of a general ward; we have found this to be the case only in the initial critical phase of noninvasive ventilation, but not so much when this phase has been overcome. Bотт et al. [8] did not observe that patients using NPPV consumed more nursing time than equally ill conventionally treated patients. Nevertheless, it is important to stress the need for experienced staff in this complex ventilatory technique [41]. In addition, the psychological support offered by the presence of patients' relatives might be very important, especially during the first hours of mask ventilation.

In conclusion, our results suggest that bi-level positive airway pressure delivered by mask can be added at an early stage to medical therapy plus oxygen supplementation in patients with acute on chronic respiratory failure due to decompensated chronic obstructive pulmonary disease in order to improve immediate and long-term outcomes.

\section{References}

1. Shmidt GA, Hall JB. Acute on chronic respiratory failure: assessment and management of patients with COPD in the emergent setting. J Am Med Assoc 1989; 261: 3444 3453.

2. Athonisen NR. Prognosis in chronic obstructive pulmonary disease: results from multicenter clinical trials. Am Rev Respir Dis 1989; 140: S95-S99.

3. Burrows B, Bloom JW, Traver GA, Cline MO. The course and prognosis of different forms of chronic airways obstruction in a sample from the general population. N Engl J Med 1987; 31: 1309-1314.

4. Ambrosino N, Nava S, Rubini F. Noninvasive mechanical ventilation in the treatment of acute respiratory failure in chronic obstructive pulmonary disease. Monaldi
Arch Chest Dis 1993; 48: 144-154.

5. Meyer TJ, Hill NS. Noninvasive positive pressure ventilation to treat respiratory failure. Ann Intern Med 1994; 120: $760-770$

6. Vitacca M. Rubini F, Foglio K, Salvini S, Nava S, Ambrosino N. Noninvasive modalities of positive pressure ventilation improve the outcome of acute exacerbations in COLD patients. Intensive Care Med 1993; 19: 450-455.

7. Brochard L, Isabey D, Piquet $\mathrm{J}$, et al. Reversal of acute exacerbations of chronic obstructive lung disease by inspiratory assistance with a face-mask. N Engl J Med 1990; 323: $1523-1530$.

8. Bott J, Carrol MP, Conway JH, et al. Randomised controlled trial of nasal ventilation in acute failure due to chronic obstructive airways disease. Lancet 1993; 341 : $1555-1557$.

9. Confalonieri M, Aiolfi S, Gandola L, Scartabellati A, Della Porta R, Parigi P. Severe exacerbations of chronic obstructive pulmonary disease treated with BiPAP ${ }^{\circledR}$ by nasal mask. Respiration 1994; 61: 310-316.

10. Jeffery AA, Warren PM, Flenley DC. Acute hypercapnic respiratory failure in patients with chronic obstructive lung disease: risk factors and use of guidelines for managements. Thorax 1992; 47: 34-40.

11. Braghiroli A, Donner CF. Bi-level positive airway pressure. Eur Respir Rev 1992; 2: 398-399.

12. Strumpf DA, Carlisle CC, Millman RP, Smith KW, Hill NS. An evaluation of the Respironics BiPAP bi-level CPAP device for delivery of assisted ventilation. Respir Care 1990; 35: 415-422.

13. Ferguson GT, Marion J, Gilmartin M. Effect of various exhalation ports on $\mathrm{CO}_{2}$ rebreathing during BiPAP® ventilatory assistance. Am J Respir Crit Care Med 1994; 149: A638.

14. Kaplan G, Meier P. Nonparametric estimation from incomplete observations. J Am Stat Assoc 1958; 53: 457-481.

15. Peto R, Pike MC, Armitage P, et al. Design and analysis of randomized clinical trials requiring prolonged observation in each patient: analysis and examples. $\mathrm{BrJ}$ Cancer 1977; 35: 1-39.

16. Burrows B, Bloom JW, Traver GA, Cline MO. The course and prognosis of different forms of chronic airways obstruction in a sample from the general population. $N$ Engl J Med 1987; 31: 1309-1314.

17. Nava S, Rubini F, Zanotti E, et al. Survival and prediction of successful ventilator weaning in COPD patients requiring mechanical ventilation for more than 21 days. Eur Respir J 1994; 7: 1645-1652.

18. Menzies R, Gibbons W, Goldberg P. Determinants of weaning and survival among patients with COPD who require mechanical ventilation for acute respiratory failure. Chest 1989; 95: 398-405.

19. Gillespie DJ, Marsh HMM, Divertie MB, Meadows JA. Clinical outcome of respiratory failure in patients requiring prolonged $(>24 \mathrm{~h})$ mechanical ventilation. Chest 1986; 90: 364-369.

20. Kaelin R, Assimacopoulos A, Chevrolet JC. Failure to predict 6 months survival of patients with COPD requiring mechanical ventilation by analysis of simple indices: a prospective study. Chest 1992; 101: 211-214.

21. Corrado A, Bruscoli G, Messori A, et al. Iron lung treatment of subjects with COPD in acute respiratory failure: evaluation of short- and long-term prognosis. Chest 1992; 101: 692-696.

22. Corrado A, DePaola E, Messori A, Bruscoli G, Nutini S. The effect of intermittent negative pressure ventilation and long-term oxygen therapy for patients with 
COPD: a 4 year study. Chest 1994; 105: 95-99.

23. Meecham Jones DJ, Paul EA, Grahame-Clarke C, Wedzicha JA. Nasal ventilation in acute exacerbations of chronic obstructive pulmonary disease: effect of ventilator mode on arterial blood gas tension. Thorax 1994; 49: 12221224.

24. Meduri GU, Abou-Shala N, Fox RC, Jones CB, Leeper $\mathrm{KV}$, Wunderink R. Noninvasive face-mask mechanical ventilation in patients with acute hypercapnic respiratory failure. Chest 1991; 100: 445-454.

25. Ambrosino N, Nava S, Bertone P, Fracchia C, Rampulla C. Physiologic evaluation of pressure support ventilation by nasal mask in patients with stable COPD. Chest 1992; 101: 385-391.

26. Similowsky T, Yan S, Gauthier AP, Macklem PT, Bellamare F. Contractile properties of the human diagphram during chronic hyperinflation. N Engl J Med 1991; 325: 917-923.

27. Appendini L, Patessio A, Zanaboni S, et al. Physiologic effects of positive end-expiratory and mask pressure support during exacerbations of chronic obstructive pulmonary disease. Am J Respir Crit Care Med 1994; 149: 1069-1076.

28. Chastre J, Fafon JY. Pneumonia in the ventilator-dependent patient. In: Tobin MJ, ed. Principles and Practice of Mechanical Ventilation. New York, McGraw-Hill, 1994; pp. 857-890.

29. Sottile FD, Marrie TJ, Prough DS, et al. Nosocomial pulmonary infection: possible etiologic significance of bacterial adhesion to endotracheal tubes. Crit Care Med 1986; 14: 265-270.

30. Sacks H, Chalmers TC, Smith H Jr. Randomized versus historical controls for clinical trials. Am J Med 1982; 72: 233-240.

31. Monasterio C, Escarrabill J, Manresa F, Estopá R. Nasal ventilation in acute respiratory failure (letter). Lancet
1993; 342: 503.

32. Bland JM, Altman DG. Matching. Br Med J 1994; 309: 1128.

33. Knaus WA, Draper EA, Wagner DP, Zimmermen JE. Apache II: a severity of disease classification system. Crit Care Med 1985; 13: 818-829.

34. Pennock BE, Kaplan PD, Carlin BW, Sabangal JS, Mogovern JA. Pressure support ventilation with a simplified ventilatory support system administered with a nasal mask in patients with respiratory failure. Chest 1991; 100: 1371-1376.

35. Nava S, Ambrosino N, Rubini F, et al. Effect of nasal pressure support ventilation and external PEEP on diaphragmatic activity in patients with severe stable COPD. Chest 1993; 103: 143-150.

36. Smith TC, Marini JJ. Impact of PEEP on lung mechanics and work of breathing in severe airflow obstruction. J Appl Physiol 1988; 65: 1488-1499.

37. Rossi A, Brandolese R, Milic-Emili J, Gottfried SB. The role of PEEP in patients with chronic obstructive pulmonary disease during assisted ventilation. Eur Respir J 1990; 3: 818-822.

38. Pennock BE, Craswshaw L, Kaplan PD. Noninvasive nasal mask ventilation for acute respiratory failure: institution of a new therapeutic technology for routine use. Chest 1994; 105: 441-444.

39. Conway JH, Hitchcock RA, Godfrey RC, Carroll MP. Nasal intermittent positive pressure ventilation in acute exacerbations of chronic obstructive pulmonary disease: a preliminary study. Respir Med 1993; 87: $387-$ 394.

40. Chevrolet JC, Jolliet P, Abajo B, Toussi A, Louis M. Nasal positive pressure ventilation in patients with acute respiratory failure. Difficult and time-consuming procedure for nurses. Chest 1991; 100: 775-782.

41. Brochard L. Noninvasive ventilation: practical issues. Intensive Care Med 1993; 19: 431-432. 